This document is the Accepted Manuscript version of a Published Work that appeared in final form in Jouranl of Physical Chemistry C, copyright (C) American Chemical Society after peer review and technical editing by the publisher. To access the final edited and published work see http://pubs.acs.org/doi/abs/10.1021/acs.jpcc.5b05018.

\title{
Adsorption of Methylene Fluoride and Methylene Chloride at the Surface of Ice under Tropospheric Conditions. A Grand Canonical Monte Carlo Simulation Study
}

Ildikó Sumi $^{\mathrm{a}}$, Sylvain Picaud ${ }^{\mathrm{b}}$, Pál Jedlovszky ${ }^{\mathrm{a}, \mathrm{c}, \mathrm{d}, *}$

${ }^{a}$ EKF Department of Chemistry, Leányka u. 6, H-3300 Eger, Hungary

${ }^{\mathrm{b}}$ Institut UTINAM (CNRS UMR 6213), Université de Franche-Comté, 16 route de Gray, F-25030 Besançon, France

${ }^{c} M T A-B M E$ Research Group of Technical Analytical Chemistry, Szt. Gellért tér 4, H-1111 Budapest, Hungary

${ }^{\mathrm{d}}$ Laboratory of Interfaces and Nanosize Systems, Institute of Chemistry, Eötvös Loránd University, Pázmány P. Stny 1/A, H-1117 Budapest, Hungary

This paper is dedicated to the memory of Martina Roeselova

Running title: Adsorption of $\mathrm{CH}_{2} \mathrm{~F}_{2}$ and $\mathrm{CH}_{2} \mathrm{Cl}_{2}$ on ice 
*E-mail: pali@chem.elte.hu, phone : +36-13722500/1552 


\begin{abstract}
:
The adsorption of two halogenated methane derivatives, namely methylene fluoride and methylene chloride at the surface of $\mathrm{I}_{\mathrm{h}}$ ice is studied by grand canonical Monte Carlo simulations under tropospheric conditions. The adsorption isotherms of the two molecules, differing only in the halogen atom type, are found to be markedly different from each other. Thus, while methylene fluoride exhibits multilayer adsorption, and its adsorption isotherm belongs to class II according to the IUPAC convention, methylene chloride does not show considerable adsorption at the ice surface, as its condensation well precedes the saturation of even the first adsorbed molecular layer. Interestingly, both the surface orientation and the binding energy of the two types of adsorbed molecules are rather similar to each other; first layer molecules form one single hydrogen bond with the dangling $\mathrm{OH}$ groups of the ice surface. The strong differences in the adsorption behavior of methylene fluoride and methylene chloride are traced back to the different cohesion in the liquid phase, and hence to the strongly different boiling point of the two molecules.
\end{abstract}




\section{Introduction}

The study of interactions between trace gases and ice surfaces has been of increasing interest in recent decades since the recognition of the crucial role that ice surfaces can play in catalytic ozone destruction resulting from halogen activation in the polar stratosphere ${ }^{1}$ and, more recently, in partitioning organic compounds from gas to ice phases in the troposphere. ${ }^{2}$ In addition, these interactions play a key role in possible scavenging of organic compounds, and, more generally, atmospheric pollutant molecules by falling snow. ${ }^{3}$ Moreover, recent evidence has also shown that sequestration of persistent organic pollutants in all snow-covered regions of the globe can have a significant influence on the overlying atmosphere. ${ }^{4,5}$

As mentioned above, ice-halogen chemistry was first explored for its implication into the formation of the Antarctic ozone hole, a phenomenon in which the majority of ozone within the polar stratospheric vortex is depleted annually for months at a time. ${ }^{1}$ It has thus been shown that halogens released from ice particles interacting with long-lived anthropogenic substances, such as chlorofluorocarbons (CFCs) in Polar Stratospheric Clouds (PSCs) are the principal cause for subsequent chemical reactions leading to ozone consumption. As a consequence, since 1987 and the signature of the Montreal Protocol by developed and developing countries, the global production and use of CFCs and halons have decreased significantly, being progressively replaced first by hydrochlorofluorocarbons (HCFCs) considered as "transitional substitutes" and, in a second step, by hydrofluorocarbons (HFCs). ${ }^{6}$ Indeed, like CFCs, these compounds are good refrigerants and can be used as aerosol propellants because of their low flammability. ${ }^{7}$ However, if HFCs do not harm the ozone layer like the compounds they replace, they are now suspected to contribute to global warming and, because their atmospheric concentrations are rapidly increasing, their contribution to anthropogenic greenhouse gas emissions is causing international concern about their radiative forcing. 8,9

Moreover, because of their gas phase chemical properties, HFCs are long-lived (from tens of months to tens of years) halogen substances in the atmosphere, ${ }^{10}$ and it is thus important to know whether they can be scavenged or not from the gas phase, for instance by dissolution into water droplets or trapping at the surface of ice particles. Surprisingly, the interaction of such molecules with ice surfaces has not been much studied in the literature and we are aware 
of only a very small number of related papers. Thus, Holmes and Sodeau studied the interaction between a series of twenty-three halogenocarbon compounds and water-ice at 12 K by using infrared (IR) spectroscopy measurements. ${ }^{11}$ They found that all these molecules interact through lone pair donation from a halogen atom to a dangling hydrogen atom of the water molecules at the surface of ice. Interestingly, however, they also evidenced that the corresponding $\mathrm{H}$-dangling bond IR shift strongly depends on the nature of the halogenocarbon molecule. On the other hand, Vysokikh et al. focused on the interaction of ozone with chlorinated methane derivatives adsorbed on a thin ice film over the temperature range of 77-292 K, and confirmed that these compounds are not potential ozone layer destroying agents because they cannot dissociate on ice and release chlorine, at least up to $220 \mathrm{~K} .^{12}$

Experimental investigations of the problem can be very well complemented by computer simulation studies, since in a computer simulation a detailed, atomistic level insight is obtained into the three dimensional structure of the appropriately chosen model of the system of interest. In this respect, grand canonical Monte Carlo (GCMC) simulations ${ }^{13,14}$ are of particular importance. Namely, in a GCMC simulation the chemical potential rather than the number of molecules of a given compound is fixed in the basic simulation box. Thus, performing a set of GCMC simulations in which the chemical potential of the adsorbate molecules is systematically varied, the number of the adsorbed molecules per surface unit vs. the chemical potential, i.e., the adsorption isotherm can easily be determined from extremely low pressures up to the point of condensation. Indeed, the GCMC method has been successfully applied to calculate the adsorption isotherms of water and other small molecules at various different solid surfaces, such as at carbonaceous materials, ${ }^{15-23}$ self-assembled monolayers, ${ }^{24,25}$ covalent organic frameworks, ${ }^{26-28}$ protein crystals, ${ }^{29}$ metal oxides, ${ }^{30-33}$ zeolites, ${ }^{34-41}$ kaolinite, $^{42-44}$ and ice. ${ }^{45-53}$ Further, besides the adsorption isotherms themselves, the structure and energetics of the adsorption layer can also be analyzed in detail in such simulations. However, we are not aware of any simulation or other theoretical studies (e.g., $a b$ initio calculations) of the adsorption of halogenocarbon molecules at the surface of ice.

Considering both of the aforementioned experimentally observed features, i.e., nondissociative adsorption of halogenocarbon compounds on ice at temperatures typical of the lower stratosphere/upper troposphere regions, ${ }^{11}$ and differences in the interactions between ice and different halomethanes, ${ }^{12}$ and also the lack of theoretical investigations on these systems, 
here we perform a detailed investigation of the adsorption behavior of two different halogenocarbon molecules, namely methylene fluoride $\left(\mathrm{CH}_{2} \mathrm{~F}_{2}\right)$ and methylene chloride $\left(\mathrm{CH}_{2} \mathrm{Cl}_{2}\right)$ at the surface of $\mathrm{I}_{\mathrm{h}}$ ice under tropospheric conditions by performing GCMC simulations. The two molecules considered differ only in the type of the halogen atoms (i.e., F vs. Cl). Besides the adsorption isotherms, the layering of the adsorbed molecules as well as the orientation and binding energy of the adsorbed molecules that are in direct contact with the ice phase are also analyzed in detail. The paper is organized as follows. In sec. 2 details of the calculations performed are given. The obtained results are presented in sec. 3 , and in sec. 4 the main conclusions of this study are discussed and summarized.

\section{Computer Simulations}

The adsorption of methylene fluoride and methylene chloride at the (0001) surface of hexagonal $\left(\mathrm{I}_{\mathrm{h}}\right)$ ice has been investigated by performing a set of Monte Carlo simulations on the grand canonical $(\mu, V, T)$ ensemble, in which the chemical potential of the adsorbate, $\mu$, has been systematically varied, and the average number of the adsorbed molecules, $\langle N\rangle$, has been determined as a function of $\mu$. The simulations have been performed at the tropospheric temperature of $200 \mathrm{~K}$. The $X, Y$ and $Z$ edges of the basic simulation box have been 100.0, 38.891, and $35.926 \AA$ long, respectively, $X$ being the surface normal axis. The ice phase has consisted of 2880 water molecules, arranged in 18 molecular layers along the surface normal axis, $X$. The chemical potential of methylene fluoride and methylene chloride has been varied in the ranges from -45.13 to $-25.18 \mathrm{~kJ} / \mathrm{mol}$, and from -46.36 to $-30.56 \mathrm{~kJ} / \mathrm{mol}$, respectively. These chemical potential ranges cover the range of systems from those containing practically no adsorbate molecules to those when the simulation box is completely filled. The chemical potential values of methylene fluoride and methylene chloride used in the simulations are summarized in Tables 1 and 2, respectively.

Methylene fluoride has been described by the five site potential model of Jedlovszky and Mezei, ${ }^{54}$ whereas for methylene chloride the five site model of Ferrario and Evans ${ }^{55}$ has been used, with the geometry parameters proposed by Kneller and Geiger. ${ }^{56}$ Water molecules have been described by the five-site TIP5P potential model. ${ }^{57}$ The choice of this water model has been dictated by the fact that it reproduces the melting point of $I_{h}$ ice very accurately, 
within a few Kelvin. ${ }^{58,59}$ All potential models have been rigid; the interaction energy of a molecule pair has been calculated as the sum of the Lennard-Jones and charge-charge Coulomb contributions of all of their interaction site pairs, and the total potential energy of the system has been calculated as the sum of the interaction energies of all molecule pairs. The interaction and geometry parameters of the potential models used are summarized in Tables 3 and 4, respectively. All interactions have been truncated to zero beyond the center-center cut-off distance of $12.5 \AA$. In accordance with the original parameterization of the TIP5P model, ${ }^{57}$ no long-range correction has been applied. As we showed previously on the example of the adsorption of acetone on ice, the long-range correction of the electrostatic interaction has a negligible effect on the adsorption isotherm. ${ }^{48}$

The simulations have been performed using the program MMC. ${ }^{60}$ In a Monte Carlo step either a randomly chosen molecule (water or adsorbate) has been randomly translated by no more than $0.25 \AA$ and randomly rotated around a randomly chosen space-fixed axis by no more than $15^{\circ}$, or an adsorbate molecule has been attempted to be randomly added to or removed from the system. Water molecules of the two middle layers have not been selected for move. Particle displacement and insertion/deletion steps have been performed in an alternating order; insertion and deletion attempts have been done with 50\%-50\% probabilities. Insertion/deletion attempts have been performed using the cavity biased algorithm of Mezei, ${ }^{61,62}$ thus, insertions have only been attempted into the centers of empty cavities of the radius of at least $2.5 \AA$. Cavities have been searched for along a $100 \times 100 \times 100$ grid. Insertion/deletion attempts have been accepted or rejected according to the acceptance rule of the cavity biased method, ${ }^{61,62}$ whereas for the acceptance of the particle displacement steps the standard Metropolis criterion $^{14,63}$ has been applied. This way, at least $10 \%$ of the particle displacement steps and $0.1 \%$ of the insertion/deletion attempts have been successful in every case.

The simulations started from the perfect arrangement of the water molecules in the $I_{h}$ ice crystal, having two adsorbate molecules placed randomly in the vapor phase. The ice phase has been placed in the middle of the basic simulation box along the surface normal axis, $X$. Periodic boundary conditions have been applied in all three directions. Due to the periodic boundary conditions, the basic box has contained two ice-vapor interfaces, at the same distance from the center of the basic box along axis $X$ in both directions. The systems have been equilibrated by performing $3-5 \times 10^{8}$ Monte Carlo steps. The average number of the adsorbed 
molecules in the basic box, $\langle N\rangle$, has then been calculated over $10^{8}$ equilibrium sample configurations. Finally, at selected chemical potential values 2500 sample configurations, separated by $2 \times 10^{5}$ Monte Carlo steps each, have been saved for further analyses.

\section{Results}

3.1. Adsorption Isotherms. The adsorption isotherms obtained from the simulations are shown in Figure 1 in the form of average number of the adsorbed molecules, $\langle N\rangle$, vs. the adsorbate chemical potential, $\mu$, whereas the corresponding data are collected in Tables 1 and 2. As is seen, the two adsorption isotherms are rather strongly different from each other. Thus, methylene chloride adsorbs only very weakly, and condensation (i.e., abrupt filling of the simulation box) occurs at rather low surface coverage, at the chemical potential value of $\mu=-35.13 \mathrm{~kJ} / \mathrm{mol}$. On the other hand, the adsorption layer of methylene fluoride gets progressively more saturated with increasing chemical potential, and turns to a sharp increase around $\mu=-27 \mathrm{~kJ} / \mathrm{mol}$. However, the filling of the box occurs much less abruptly than in the case of methylene chloride, suggesting that the adsorption might well involve several molecular layers. Therefore, the detection of the point of condensation as the $\mu$ value at which the box is filled with methylene fluoride molecules might be subject of systematic error. This error is due to finite size effect, namely that the two situations when (i) methylene fluoride condenses, and (ii) the thickness of the adsorption layer gets comparable with the vapor phase of the basic box cannot be distinguished. Therefore, we detected the point of condensation of methylene fluoride by performing a set of GCMC simulations without the presence of the ice phase. Since in this case no adsorption can occur, the chemical potential value corresponding to the abrupt filling of the simulation box can be unambiguously identified as the point of condensation. $^{25}$ This way, the chemical potential value corresponding to the point of condensation of methylene fluoride resulted in $\mu=-24.43 \mathrm{~kJ} / \mathrm{mol}$, indeed well above the point at which the ice-containing simulation box gets filled. The more than $10 \mathrm{~kJ} / \mathrm{mol}$ difference in the chemical potential values corresponding to the condensation of methylene chloride and methylene fluoride is in a full accordance with the fact that the boiling point of methylene chloride is much higher, being $313.2 \mathrm{~K},{ }^{64}$ than that of methylene fluoride of $221.5 \mathrm{~K} .{ }^{64}$ 
According to the shape of the adsorption isotherms, we have selected five chemical potential values for methylene fluoride, and three chemical potential values for methylene chloride at which sample configurations have been collected for detailed analysis These state points, denoted by MeF I, MeF II, MeF III, MeF IV, and MeF V, respectively, and MeCl I, $\mathrm{MeCl}$ II, and $\mathrm{MeCl}$ III, respectively, are indicated in Tables 1 and 2, and also marked by arrows in Figure 1. Equilibrium snapshots of these systems are shown in Figure 2a-b both in top and side views.

To further analyze the obtained adsorption isotherms we have converted them to the more conventional $\Gamma$ vs. $p_{\text {rel }}$ form, where $\Gamma$ is the surface density of the adsorbed molecules, and $p_{\text {rel }}=p / p_{0}$ is the relative pressure, i.e., the pressure normalized by that of the point of condensation, $p_{0} . \Gamma$ and $p_{\text {rel }}$ are related to $\langle N\rangle$ and $\mu$ through the simple relations

$$
\Gamma=\frac{<N>}{2 Y Z}
$$

and $^{32}$

$$
p_{\text {rel }}=\frac{p}{p_{0}}=\frac{\exp \left(\mu / k_{\mathrm{B}} T\right)}{\exp \left(\mu_{0} / k_{\mathrm{B}} T\right)}
$$

where $k_{\mathrm{B}}$ is the Boltzmann constant, $\mu_{0}$ is the chemical potential value corresponding to the point of condensation, $Y Z$ is the cross section area of the basic simulation box, and the factor of 2 in the denominator of eq. 1 accounts for the two ice surfaces present in the basic box.

The obtained $\Gamma$ vs. $p_{\text {rel }}$ adsorption isotherms are presented in Figure 3 , and the corresponding data are also included in Tables 1 and 2. As is seen, the shape of the adsorption isotherm of methylene fluoride corresponds to class II isotherms according to the IUPAC convention. Thus, at low $p_{\text {rel }}$ values, up to about 0.1 the steepness of the isotherm decreases gradually. Around this $p_{\text {rel }}$ value it goes through an inflection point, and further increase of the pressure leads to an increasing steepness of the isotherm, indicating multilayer adsorption. The simulated data points can be very well fitted by the formula of the Langmuir isotherm, ${ }^{65,66}$

$$
\Gamma=\frac{\Gamma_{\max } p_{\text {rel }} K}{1+p_{\text {rel }} K}
$$


up to the data point at $p_{\text {rel }}=0.052$, as is also shown in Figure 3. However, adding more simulated data points, at higher relative pressures, to the fitting procedure the quality of the fit gets progressively worse, indicating that outer molecular layers start to be built up above this pressure. The parameters $\Gamma_{\max }$ and $K$ are the surface density of the saturated monolayer and the Langmuir partition coefficient, respectively; their values are resulted in $\Gamma_{\max }=8.73 \mu \mathrm{mol} / \mathrm{m}^{2}$ and $K=37.4$, respectively. At larger $p_{\text {rel }}$ values, the multilayer adsorption exhibited by methylene fluoride on ice can rather be described in terms of the Brunauer-Emmett-Teller (BET) isotherm, ${ }^{66}$

$$
\Gamma=\Gamma_{\text {mono }} \frac{p_{\text {rel }} C}{\left(1-p_{\text {rel }}\right)\left[1+(C-1) p_{\text {rel }}\right]},
$$

where $\Gamma_{\text {mono }}$ is the surface density of the saturated monolayer, and $C$ is the BET coefficient, related to the energetics of the adsorption. BET isotherms are usually presented by showing $p_{\text {rel }} / \Gamma\left(1-p_{\text {rel }}\right)$ instead of $\Gamma$ as a function of $p_{\text {rel: }}$

$$
\frac{p_{\text {rel }}}{\Gamma\left(1-p_{\text {rel }}\right)}=\frac{1}{\Gamma_{\text {mono }} C}+\frac{C-1}{\Gamma_{\mathrm{mono}} C} p_{\text {rel }},
$$

since in this form the isotherm is linear, at least up to moderate $p_{\text {rel }}$ values. Considering that the calculated isotherm exhibits such a linear behavior up to the $p_{\text {rel }}$ value of about 0.15 , we have fitted the linearized form of the BET isotherm up to this relative pressure value, and obtained the $\Gamma_{\text {mono }}$ value of $9.98 \mathrm{mmol} / \mathrm{m}^{2}$, in a reasonable agreement with the $\Gamma_{\max }$ value determined from the Langmuir analysis. The fit of the BET isotherm to the simulated data is also shown in Figure 3.

The $\Gamma\left(p_{\text {rel }}\right)$ isotherm of methylene chloride, on the other hand, rises, within error bars, nearly linearly in the entire $p_{\text {rel }}$ interval from 0 to 1 , being the surface coverage still very low at the point of condensation (see the inset of Fig. 3). This finding indicates that condensation well precedes the building up of even the first molecular layer; the nearly linear shape of the isotherm indicates that the adsorption of the individual molecules is still practically independent from each other even at the vicinity of the point of condensation. 
3.2. Density Profiles. To characterize the adsorption layer, we have calculated the density profile of the adsorbed molecules along the surface normal axis, $X$, at the chemical potential values where sample configurations had been collected for detailed analyses. The obtained density profiles, being symmetrized over the two ice surfaces present in the basic box, are shown in Figure 4. For reference, the water number density profile is also shown.

As is seen, in systems MeF I, MeF II, and MeF III the first molecular layer of the adsorbed molecules is building progressively up. In the system MeF III some traces of the second molecular layer are also present, although the first layer is still not fully saturated yet. In the chemical potential range between systems MeF III and MeF IV the first layer gets saturated simultaneously with the continuous building up of the outer layers. In system MeF IV the first layer is already saturated, and both the second and third layers are visible, both still being built up. Finally, in system MeF V the simulation box is filled by methylene fluoride molecules; the density profile shows liquid-like oscillation, and at least five separate consecutive molecular layers can be distinguished. It should be emphasized that in this system methylene fluoride is still well below its point of condensation ( $p_{\text {rel }}$ being only 0.235 , see Table 1), in spite of the fact that the basic box is already filled.

By contrast, the density profile of methylene chloride exhibits one single small peak, below the point of condensation, i.e., in systems $\mathrm{MeCl}$ I and $\mathrm{MeCl}$ II, in accordance with the behavior of the adsorption isotherm. In system $\mathrm{MeCl}$ III methylene chloride is already condensed; the basic box is filled with liquid methylene chloride.

To get a deeper insight into the mechanism of the adsorption, we further analyze the first layer of the adsorbed molecules in terms of orientation relative to the surface, and binding energy. For this purpose, however, the outer boundary of the first molecular layer has to be defined. This can be done through the first minimum position of the density profiles in systems where more than one molecular layers are present (i.e., systems MeF IV, MeF V, and system $\mathrm{MeCl}$ III). This way, the outer boundary of the first adsorbed molecular layer is found to be at $X=35.8 \AA$ in the case of methylene fluoride, and $X=36.5 \AA$ for methylene chloride.

3.3. Orientation of the Molecules in the First Adsorbed Layer. To get a deeper insight into the background of adsorption and investigate the possible differences between the adsorption mechanisms of methylene fluoride and methylene chloride, we have analyzed the 
orientational preferences of the adsorbed molecules belonging to the first molecular layer, i.e., being in direct contact with the ice phase, for both adsorbates. The full description of the orientational statistics of rigid bodies (in our case, adsorbed molecules) relative to an external direction (in this case, the surface normal axis, $X$ ) requires the calculation of the bivariate distribution of two independent orientational variables. ${ }^{67,68} \mathrm{We}$ have shown that the angular polar coordinates $\vartheta$ and $\phi$ of the surface normal vector, $\underline{X}$, (pointing away from the ice phase by our convention) in a local Cartesian frame fixed to the individual first layer molecules is a sufficient choice of such an orientational variable pair. ${ }^{67,68}$ Here we define this local Cartesian frame in the following way. Its axes $x$ and $y$ are parallel with the lines joining the two hydrogen and two halogen atoms, respectively, while its axis $z$ is the main symmetry axis of the molecule, pointing from the bisector of the two $\mathrm{H}$ atoms towards that of the two halogen atoms. Due to the $\mathrm{C}_{2 \mathrm{v}}$ symmetry of the methylene chloride and methylene fluoride molecules, this frame is always chosen in such a way that the inequality $0^{\circ} \leq \phi \leq 90^{\circ}$ is satisfied. The definition of this local frame as well as that of the polar angles $\vartheta$ and $\phi$ is illustrated in Figure 5. It should also be noted that since $\vartheta$ is an angle between two general spatial vectors, but $\phi$ is formed by two vectors restricted to lay in a given plane (i.e., the $x y$ plane of the local frame) by definition, uncorrelated orientation of the molecules with the surface results in a uniform distribution only if $\cos \vartheta$ and $\phi$ are chosen to be the orientational variables.

The $P(\cos \vartheta, \phi)$ orientational maps of the adsorbed methylene fluoride and methylene chloride molecules are shown in Figure 6 as obtained in the different systems analyzed. As is seen, the obtained $P(\cos \vartheta, \phi)$ maps are rather similar to each other in every case. Thus, all these maps have two separate peaks, indicating a dual orientational preference of the adsorbed molecules. The first of these peaks is located around the $\left\{\cos \vartheta=-0.3 ; \phi=90^{\circ}\right\}$ point, whereas the other peak appears at $\cos \vartheta=-1$ and $\phi=0^{\circ}$. These peaks are denoted here by I and II, respectively. In the orientation corresponding to peak I one of the halogen atoms of the adsorbed molecule points straight to the ice phase, while the other halogen and the two hydrogen atoms point flatly away from it. In this orientation the adsorbed molecule can form $\mathrm{H}$-bonds with surface water molecules that point one of their $\mathrm{H}$ atoms flatly towards the adsorption layer, as it is in two of the four preferred orientations of the water molecules at the surface of the ice phase. ${ }^{45}$ In orientation II, the main symmetry axis of the adsorbed molecule stays perpendicular to the ice surface, the halogen atoms pointing towards, whereas the 
hydrogen atoms away from the ice phase. In this orientation the halogen atoms of the adsorbed molecule can also participate in a hydrogen bond with a surface water by accepting its dangling $\mathrm{H}$ atom. This finding is in a clear agreement with the experimental result of Holmes and Sodeau, who observed, by performing IR spectroscopy measurements, that halomethane molecules adsorbed at the surface of amorphous ice form hydrogen bonds with the surface water molecules by accepting their dangling $\mathrm{H}$ atoms. ${ }^{11}$ The preferred orientations I an II of the adsorbed molecules are illustrated in Fig. 6, whereas the possible hydrogen bonding arrangements between the adsorbed molecules and surface waters, both being in one of their preferred alignments, is illustrated in Figure 7.

3.4. Binding Energy of the Molecules at the Ice Surface. The observed preferred orientations of the adsorbed molecules allow the formation of several (i.e., up to three in orientation I, and up to two in orientation II) hydrogen bonds between an adsorbed molecule and the surface waters. To further investigate this point and get an insight into the energetic background of the adsorption, we have calculated the distribution of the total binding energy of the adsorbed molecules being in contact with the ice phase, $U_{\mathrm{b}}$, and also that of its separate contributions coming from the interaction with the ice phase and with the other adsorbed molecules, $U_{\mathrm{b}}^{\text {ice }}$, and $U_{\mathrm{b}}^{\text {lat }}$, respectively. The binding energy of an adsorbed molecule is the energy cost of bringing this molecule to an infinite distance from the rest of the system; in other words, it is the energy of its interaction with the rest of the system. Since the potential models used in this study are pairwise additive, ${ }^{54-56}$ the $U_{\mathrm{b}}$ total binding energy can simply be calculated by summing up the pair interaction energies of the given adsorbed molecule with all the other molecules in the system. Similarly, $U_{\mathrm{b}}^{\text {ice }}$ and $U_{\mathrm{b}}^{\text {lat }}$ are the sums of the interaction energies of this adsorbed molecule with all the water molecules, and with all the other adsorbed molecules in the system, respectively.

The obtained binding energy distributions are shown in Figure 8a-b. As is seen, the different distributions obtained for methylene fluoride and methylene chloride are again surprisingly similar to each other. Thus, at low surface coverages (i.e., in systems MeF I, MeF II, $\mathrm{MeCl}$ I and $\mathrm{MeCl}$ II $)$ the $P\left(U_{\mathrm{b}}^{\text {ice }}\right)$ distribution exhibits one single peak around the 
$U_{\mathrm{b}}^{\text {ice }}$ value of $-27 \mathrm{~kJ} / \mathrm{mol}$ (in the case of methylene fluoride) and $-20 \mathrm{~kJ} / \mathrm{mol}$ (in the case of methylene chloride). Considering the fact that the energy of a hydrogen bond is roughly $-20 \mathrm{~kJ} / \mathrm{mol}$, this finding clearly indicates that, in spite of the orientational possibility of multiple hydrogen bonding, adsorbed molecules form only one single hydrogen bond with the surface waters. This hydrogen bond is considerably stronger in the case of methylene fluoride, in accordance with the well known experimental fact that the electronegativity of the atoms (and hence their $\mathrm{H}$-accepting ability) decreases with increasing size within the individual groups of the periodic table (e.g., from fluorine to chlorine). With increasing surface coverage this peak of $P\left(U_{\mathrm{b}}^{\text {ice }}\right)$ shifts to higher (i.e., smaller in magnitude) energy values, and in systems where a considerable number of adsorbed (or condensed) molecules are present beyond the first molecular layer (i.e., systems MeF IV, MeF V and $\mathrm{MeCl}$ III), the distribution even exhibits a shoulder at its high energy side. The aforementioned shift reflects the increasing competition of the adsorbed molecules at the surface, whereas the shoulder is due to a nonnegligible fraction of the first layer molecules that are not forming hydrogen bonds with the ice phase.

In systems of low surface coverages the $P\left(U_{\mathrm{b}}^{\text {lat }}\right)$ distribution has a large, trivial peak at zero energy, reflecting the presence of adsorbed molecules that are separated from each other. With increasing surface coverage this peak becomes lower, another peak occurs at negative $U_{\mathrm{b}}^{\text {lat }}$ values, and it is shifted to lower energies with increasing surface coverage, reflecting the increasing importance of the lateral interactions. In the system MeF III the trivial peak at $U_{\mathrm{b}}^{\text {lat }}=0$ has already completely vanished, in accordance with the fact that the first layer of this system is already close to be saturated (see Fig. 4), and hence there are no isolated molecules in the adsorption layer of this system. Finally, in the systems containing several layers of the adsorbed/condensed molecules the $P\left(U_{\mathrm{b}}^{\text {lat }}\right)$ distribution is of Gaussian shape, being centered at the $U_{\mathrm{b}}^{\text {lat }}$ values of $-23 \mathrm{~kJ} / \mathrm{mol}$ and $-40 \mathrm{~kJ} / \mathrm{mol}$ in the case of methylene fluoride and methylene chloride, respectively. In these cases the $U_{\mathrm{b}}^{\text {lat }}$ binding energy contribution comes from the entire condensed phase of the adsorbed molecules, and therefore it characterizes the cohesion of the molecules in the condensed phase rather than the energetics of the adsorption. 
In accordance with the above findings, the distribution of the total binding energy, $P\left(U_{\mathrm{b}}\right)$, is of Gaussian shape in every case, and these distributions are rather close to each other in systems having only one molecular layer of adsorbed molecules (i.e., MeF I, MeF II and MeF III, and $\mathrm{MeCl} \mathrm{I}$ and $\mathrm{MeCl} \mathrm{II}$ ), and also in systems consisting of several adsorbed molecular layers (i.e., MeF IV and MeF V). In the case of the monolayer systems this peak is centered at $-28 \mathrm{~kJ} / \mathrm{mol}$ (for methylene fluoride) and $-21 \mathrm{~kJ} / \mathrm{mol}$ (for methylene chloride), whereas in the case of multilayer systems the peak position is around $-40 \mathrm{~kJ} / \mathrm{mol}$ (for methylene fluoride) and $-57 \mathrm{~kJ} / \mathrm{mol}$ (for methylene chloride).

\section{Discussion and Summary}

In this paper we have analyzed in detail the adsorption of methylene fluoride and methylene chloride at the surface of $I_{h}$ ice under tropospheric conditions. Our results have revealed that the adsorption behavior of these two molecules is markedly different from each other. Thus, while methylene fluoride adsorbs at the surface of ice in several molecular layers, its adsorption isotherm being in class II according to the IUPAC convention, no considerable adsorption of methylene chloride has been observed up to its point of condensation. From the fitting of the Langmuir isotherm to the low surface coverage part of the adsorption isotherm the surface density of the saturated methylene fluoride monolayer turned out to be $8.73 \mu \mathrm{mol} / \mathrm{m}^{2}$.

The detailed analysis of the orientational maps and binding energy distributions has revealed the reason behind this markedly different adsorption behavior. Thus, there is only a little difference between the interaction of the two molecules with the ice phase: both molecules prefer the same orientations relative to the ice surface, and both of them forms one single hydrogen bond with the surface waters. This hydrogen bond is somewhat stronger in the case of methylene fluoride, but this difference can not explain the markedly different adsorption behavior of the two molecules. A much stronger difference is seen, however, in the magnitude of the lateral interactions, in particular, in multilayer systems. As it has been pointed out, this energy reflects the cohesion of the molecules in the condensed phase rather than the energetics of the adsorption. Since the average lateral binding energy contribution in condensed methylene chloride is almost twice as large in magnitude as the same value in methylene fluoride, we can conclude that this difference in the cohesion of the condensed 
phase, reflected also in the markedly different boiling points of the two substances, ${ }^{64}$ is responsible for the different adsorption behavior of the two molecules. Namely, methylene chloride does not adsorb considerably at the surface of ice because, unlike methylene fluoride, it condenses well before the building up of even the first adsorbed molecular layer.

\section{Acknowledgements}

This project is supported by the Hungarian OTKA Foundation under project No. 104234, by the Hungarian-French Intergovernmental Science and Technology Program (BALATON) under project No. TéT_14_FR-1-2015-0017, and by CNRS in the framework of an international program for scientific cooperation (PICS). P.J. acknowledges financial support under project No. TÁMOP-4.2.1.D-15/1/KONV-2015-0013.

\section{References}

(1) Solomon, S.; Garcia, R. R.; Rowland, F. S.; Wuebbles, D. J. On the Depletion of Antarctic Ozone, Nature 1986, 321, 755-758.

(2) Abbatt, J. P. D. Interactions of Atmospheric Trace Gases with Ice Surfaces: Adsorption and Reaction. Chem. Rev. 2003, 103, 4783-4800.

(3) Lei, Y. D.; Wania, F. Is Rain or Snow a More Efficient Scavenger of Organic Chemicals? Atmos. Environ. 2004, 38, 3557-3571.

(4) Dominé, F.; Shepson, P. B. Air-Snow Interactions and Atmospheric Chemistry. Science 2002, 297, 1506-1510.

(5) Abbatt, J. P. D.; Thomas, J. L.; Abrahamsson, K.; Boxe, C.; Granfors, A.; Jones, A. E.; King, M. D.; Saiz-Lopez, A.; Shepson, P. B.; Sodeau, J.; Toohay, D. W.; Toubin, C.; von Glasow, R.; Wren, S. N.; Yang, X. Halogen Activation via Interactions with Environmental Ice and Snow in the Polar Lower Troposphere and Other Régions. Atmos. Chem. Phys. 2012, 12, 6237-6271.

(6) IPCC/TEAP (2005) Special Report: Safeguarding the Ozone Layer and the Global Climate System: Issues Related to Hydrofluorocarbons and Perfluorocarbons (Cambridge University Press, UK). 
(7) UNEP (2007) 2006 Report of the Refrigeration, Air Conditioning and Heat Pumps Technical Options Committee (United Nations Environment Programme, Nairobi, Kenya)

(8) Velders, G. J. M.; Fahey, D. W.; Daniel, J. S.; McFarland, M.; Andersen, O. The Large Contribution of Projected HFC Emissions to Future Climate Forcing. Proc. Natl. Acad. Sci. USA 2009, 106, 10949-10954.

(9) Hossaini, R.; Chipperfield, M. P.; Montzka, S. A.; Rap, A.; Dhomse, S.; Feng, W. Efficiency of Short-Lived Halogens at Influencing Climate through Depletion of Stratospheric Ozone. Nature Geoscience 2015, 8, 186-190.

(10) Forster, P.; Ramaswamy, V.; Artaxo, P.; Berntsen, T.; Betts, R.; Fahey, D. W.; Haywood, J.; Lean, J.; Lowe, D. C.; Myhre, G.; Nganga, J.; Prinn, R.; Raga, G.; Schulz M.; Van Dorland, R. 2007: Changes in Atmospheric Constituents and in Radiative Forcing. In: Climate Change 2007: The Physical Science Basis. Contribution of Working Group I to the Fourth Assessment Report of the Intergovernmental Panel on Climate Change; Solomon, S.; Qin, D.; Manning, M.; Chen, Z.; Marquis, M.; Averyt, K. B.; Tignor, M.; Miller, H. L.; Eds.; Cambridge University Press, Cambridge, 2007.

(11) Holmes, N. S.; Sodeau, J. R. A Study of the Interaction between Halomethanes and Water-Ice. J. Phys. Chem. A 1999, 103, 4673-4679.

(12) Vysokikh, T. A.; Mukhamedzyanova, D. F.; Yagodovskaya, T. V.; Savilov, S. V.; Lunin, V. V. The interaction of $\mathrm{CH}_{3} \mathrm{Cl}, \mathrm{CH}_{2} \mathrm{Cl}_{2}, \mathrm{CHCl}_{3}$, and $\mathrm{CCl}_{4}$ with Ozone on the Surface of Ice under Stratospheric Conditions. Russian J. Phys. Chem. A 2007, 81, 1836-1839.

(13) Adams, D. J. Grand Canonical Ensemble Monte Carlo for a Lennard-Jones Fluid. Mol. Phys. 1975, 29, 307-311.

(14) Allen, M. P.; Tildesley, D. J. Computer Simulation of Liquids; Clarendon: Oxford, 1987.

(15) Muller, E. A.; Rull, L. F.; Vega, L. F.; Gubbins, K. E. Adsorption of Water on Activated Carbons: a Molecular Dynamics Study. J. Phys. Chem. 1996, 100, 11891196.

(16) Samios, S.; Stubos, A. K.; Kanellopoulos, N. K.; Cracknell, R. F.; Papadopoulos, G. K.; Nicholson, D. Determination of Micropore Size Distribution from Grand Canonical 
Monte Carlo Simulations and Experimental $\mathrm{CO}_{2}$ Isotherm Data. Langmuir 1997, 13, 2795-2802.

(17) Muller, E. A.; Hung, F. R.; Gubbins, K. E. Adsorption of Water Vapor-Methane Mixtures on Activated Carbons. Langmuir 2000, 16, 5418-5424.

(18) Challa, S. R.; Sholl, D. S.; Johnson, J. K. Adsorption and Separation of Hydrogen Isotopes in Carbon Nanotubes: Multicomponent Grand Canonical Monte Carlo Simulations. J. Chem. Phys. 2002, 116, 814-824.

(19) Striolo, A.; Chialvo, A. A.; Gubbins, K. E.; Cummings, P. T. Water in Carbon Nanotubes: Adsorption Isotherms and Thermodynamic Properties from Molecular Simulation. J. Chem. Phys. 2005, 122, 234712-1-14.

(20) Moulin, F.; Picaud, S.; Hoang, P. N. M.; Pártay, L. B.; Jedlovszky, P. A Grand Canonical Monte Carlo Simulation Study of Water Adsorption on a Model Soot Particle. Mol. Simul. 2006, 32, 487-493.

(21) Moulin, F.; Picaud, S.; Hoang, P. N. M.; Jedlovszky, P. Grand Canonical Monte Carlo Simulation of the Adsorption Isotherms of Water Molecules on a Model Soot Particle $J$. Chem. Phys. 2007, 127, 164719-1-11.

(22) Hantal, Gy.; Picaud, S.; Hoang, P. N. M.; Voloshin, V. P.; Medvedev, N. N.; Jedlovszky, P. Water Adsorption Isotherms on Porous Onionlike Carbonaceous Particles. Simulations with the Grand Canonical Monte Carlo Method. J. Chem. Phys. 2010, 133, 144702-1-12.

(23) Firlej, L. ; Kuchta, B. ; Lazarewicz, A. ; Pfeifer, P. Increased $\mathrm{H}_{2}$ Gravimetric Storage Capacity in Truncated Carbon Slit Pores Modeled by Grand Canonical Monte Carlo. Carbon 2013, 53, 208-215.

(24) Szőri, M.; Jedlovszky, P.; Roeselová, M. Water Adsorption on Hydrophilic and Hydrophobic Self-Assembled Monolayers as Proxies For Atmospheric Surfaces. A Grand Canonical Monte Carlo Simulation Study. Phys. Chem. Chem. Phys. 2010, 12, 4604-4616.

(25) Szőri, M.; Roeselová, M.; Jedlovszky, P. Surface Hydrophilicity-Dependent Water Adsoprtion on Mixed Self-Assembled Monolayers of $\mathrm{C}_{7}-\mathrm{CH}_{3}$ and $\mathrm{C}_{7}-\mathrm{COOH}$ residues. A Grand Canonical Monte Carlo Simulation Study. J. Phys. Chem. C 2011, 115, 19165-19177. 
(26) Jung, D. H.; Kim, D.; Lee, T. B.; Choi, S. B.; Yoon, J. H.; Kim, J.; Choi, K.; Choi, S. H. Grand Canonical Monte Carlo Simulation Study on the Catenation Effect on Hydrogen Adsorption onto the Interpenetrating Metal-Organic Frameworks. J. Phys. Chem. B 2006, 110, 22987-22990.

(27) Garberoglio, G. Computer Simulation of the Adsorption of Light Gases in Covalent Organic Frameworks. Langmuir 2007, 23, 12154-12158.

(28) Ramsahye, N. A.; Maurin, G.; Bourelly, S.; Llewellyn, P. L.; Devic, T.; Serre, C.; Loiseau, T.; Ferey, G. Adsorption of $\mathrm{CO}_{2}$ in Metal Organic Frameworks of Different Metal Centres: Grand Canonical Monte Carlo Simulations Compared to Experiments. Adsorption 2007, 13, 461-467.

(29) Resat, H.; Mezei, M. Grand Canonical Monte Carlo Simulation of Water Positions in Crystal Hydrates. J. Am. Chem. Soc. 1994, 116, 7451-7452.

(30) Puibasset, J.; Pellenq, R. J. M. Water Adsorption on Hydrophilic Mesoporous and Place Silica Substrates: a Grand Canonical Monte Carlo Simulation Study. J. Chem. Phys. 2003, 118, 5613-5622.

(31) Puibasset, J.; Pellenq, R. J. M. Water Adsorption in Disordered Mesoporous Silica (Vycor) at $300 \mathrm{~K}$ and $650 \mathrm{~K}$ : A Grand Canonical Monte Carlo Simulation Study of Hysteresis. J. Chem. Phys. 2005, 122, 094704-1-10.

(32) Daub, C. D.; Patey G. N.; Jack, D. B.; Sallabi A. K. Monte Carlo Simulations of the Adsorption of $\mathrm{CO}_{2}$ on the $\mathrm{MgO}(100)$ Surface. J. Chem. Phys. 2006, 124, 114706-1-9.

(33) Tombácz, E.; Hajdú, A.; Illés, E.; László, K.; Garberoglio, G.; Jedlovszky, P. Water in Contact with Magnetite Nanoparticles, as Seen from Experiments and Computer Simulations. Langmuir 2009, 25, 13007-13014.

(34) Jameson, C. J.; Jameson, K.; Baello, B. I.; Lim, H. M. Grand Canonical Monte Carlo Simulations of the Distribution and Chemical Shifts of Xenon in the Cages of Zeolite NaA. 1. Distribution and Xe-129 Chemical Shifts. J. Chem. Phys. 1994, 100, 59655976.

(35) Jameson, C. J.; Jameson, K.; Lim, H. M.; Baello, B. I. Grand Canonical Monte Carlo Simulations of the Distribution and Chemical Shifts of Xenon in the Cages of Zeolite NaA. 2. Structure of the Adsorbed Fluid. J. Chem. Phys. 1994, 100, 5977-5987. 
(36) Smit, B. Grand Canonical Monte Carlo Simulations of Chain Molecules: Adsorption Isotherms of Alkanes in Zeolites. Mol. Phys. 1995, 85, 153-172.

(37) Pellenq, R. J. M.; Tavitian, B.; Espinat, D.; Fuchs, A. H. Grand Canonical Monte Carlo Simulations of Adsorption of Polar and Nonpolar Molecules in NaY Zeolite. Langmuir 1996, 12, 4768-4783.

(38) Macedonia, M. D.; Maginn, E. J. Pure and Binary Component Sorption Equilibria of Light Hydrocarbons in the Zeolite Silicalite from Grand Canonical Monte Carlo Simulations. Fluid Phase Equil. 1999, 158-160, 19-27.

(39) Rutkai, G.; Csányi, É.; Kristóf, T. Prediction of Adsorption Equilibria of WaterMethanol Mixtures in Zeolite NaA by Molecular Simulation. Mol. Simul. 2006, 32, 869-875.

(40) Kotdawala, R. R.; Ozgur Yazaydin, A.; Kazantzis, N.; Thompson, R. W. A Molecular Simulation Approach to the Study of Adsorption of Hydrogen Cyanide and Methyl Ethyl Ketone in Silicalite, Mordenite and Zeolite Beta Structures. Mol. Simul. 2007, 33, 843-850.

(41) Kristóf, T.; Csányi, É.; Rutkai, G. Prediction of Adsorption and Separation of WaterAlcohol Mixtures with Zeolite NaA. Microporous Mesoporous Mat. 2008, 114, 455464.

(42) Rutkai, G.; Kristóf, T. Molecular Simulation Study of Intercalation of Small Molecules in Kaolinite. Chem. Phys. Letters 2008, 462, 269-274.

(43) Croteau, T.; Bertram, A. K.; Patey, G. N. Adsorption and Structure of Water on Kaolinite Surfaces: Possible Insight into Ice Nucleation from Grand Canonical Monte Carlo Calculations. J. Phys. Chem. A 2008, 112, 10708-10712.

(44) Croteau, T.; Bertram, A. K.; Patey, G. N. Simulation of Water Adsorption on Kaolinite under Atmospheric Conditions. J. Phys. Chem. A 2009, 113, 7826-7833.

(45) Jedlovszky, P.; Partay, L.; Hoang, P. N. M.; Picaud, S.; von Hessberg, P.; Crowley, J. N. Determination of the Adsorption Isotherm of Methanol on the Surface of Ice. An Experimental and Grand Canonical Monte Carlo Simulation Study. J. Am. Chem. Soc. 2006, 128, 15300-15309. 
(46) Hantal, Gy.; Jedlovszky, P.; Hoang, P. N. M.; Picaud, S. Calculation of the Adsorption Isotherm of Formaldehyde on Ice by Grand Canonical Monte Carlo Simulation. J. Phys. Chem. C 2007, 111, 14170-14178.

(47) Jedlovszky, P.; Hantal, Gy.; Neuróhr, K.; Picaud, S.; Hoang, P. N. M.; von Hessberg, P.; Crowley, J. N. Adsorption Isotherm of Formic Acid on The Surface of Ice, as Seen from Experiments and Grand Canonical Monte Carlo Simulation. J. Phys. Chem. C 2008, 112, 8976-8987.

(48) Hantal, Gy.; Jedlovszky, P.; Hoang, P. N. M.; Picaud, S. Investigation of the Adsorption Behavior of Acetone at The Surface of Ice. a Grand Canonical Monte Carlo Simulation Study. Phys. Chem. Chem. Phys. 2008, 10, 6369-6380.

(49) Petitjean, M.; Hantal, Gy.; Chauvin, C.; Mirabel, P.; Le Calvé, S.; Hoang, P. N. M.; Picaud, S.; Jedlovszky, P. Adsorption of Benzaldehyde at the Surface of Ice, Studied by Experimental Method And Computer Simulation. Langmuir 2010, 26, 9596-9606.

(50) Darvas, M.; Lasne, J.; Laffon, C.; Parent, P.; Picaud, S.; Jedlovszky, P. Adsorption of Acetaldehyde on Ice as Seen From Computer Simulation and Infrared Spectroscopy Measurements. Langmuir 2012, 28, 4198-4207.

(51) Mészár, Zs. E.; Hantal, Gy.; Picaud, S.; Jedlovszky, P. Adsorption of Aromatic Hydrocarbon Molecules at the Surface of Ice, As Seen by Grand Canonical Monte Carlo Simulation. J. Phys. Chem. C 2013, 117, 6719-6729.

(52) Szőri, M.; Jedlovszky, P. Adsorption of HCN at the Surface of Ice. A Grand Canonical Monte Carlo Simulation Study. J. Phys. Chem. C 2014, 118, 3599-3609.

(53) Picaud, S.; Jedlovszky, P. Adsorption of $\mathrm{H}_{2} \mathrm{O}_{2}$ at the Surface of $\mathrm{I}_{\mathrm{h}}$ Ice, as Seen from Grand Canonical Monte Carlo Simulations. Chem. Phys. Letters 2014, 600, 73-78.

(54) Jedlovszky, P.; Mezei, M. Computer Simulation Study of Liquid $\mathrm{CH}_{2} \mathrm{~F}_{2}$ with a New Effective Pair Potential Model. J. Chem. Phys. 1999, 110, 2991-3002.

(55) Evans, M. W.; Ferrario, M. Molecular Dynamics Simulation of Liquid $\mathrm{CH}_{2} \mathrm{Cl}_{2}$ with $3 \times 3$ and $5 \times 5$ Site-Site Interactions. Adv. Molec. Rel. Int. Proc. 1982, 22, 245-249.

(56) Kneller, G. R.; Geiger, A. Molecular Dynamics Studies and Neutron Scattering Experiments on Methylene Chloride. I. Structure. Mol. Phys. 1989, 68, 487-498. 
(57) Mahoney, M.; Jorgensen, W. L. A Five-Site Model for Liquid Water and the Reproduction of The Density Anomaly by Rigid, Nonpolarizable Potential Functions. $J$. Chem. Phys. 2000, 112, 8910-8922.

(58) Nada, H.; van der Eerden, J. P. M. J. An Intermolecular Potential Model for the Simulation of Ice and Water near the Melting Point: A Six-Site Model of $\mathrm{H}_{2} \mathrm{O} . J$. Chem. Phys. 2003, 118, 7401-7413.

(59) Vega, C.; Sanz, E.; Abascal, J. L. F. The Melting Temperature of the Most Common Models of Water. J. Chem. Phys. 2005, 122, 114507-1-9.

(60) Mezei, M. MMC: Monte Carlo Program for Simulation of Molecular Assemblies. URL: http://inka.mssm.edu/ mezei/mmc.

(61) Mezei, M. A Cavity-Biased (T, V, $\mu$ ) Monte Carlo Method for the ComputerSimulation of Fluids. Mol. Phys. 1980, 40, 901-906.

(62) Mezei, M. Mol. Phys. Grand Canonical Ensemble Monte Carlo Study of Dense Liquid Lennard-Jones, Soft Spheres and Water. 1987, 61, 565-582. Erratum: 1989, 67, 12071208.

(63) Metropolis, N.; Rosenbluth, A. W.; Rosenbluth, M. N.; Teller, A. H.; Teller, E. Equation of State Calculations by Fast Computing Machines J. Chem. Phys. 1953, 21 1087-1093.

(64) CRC Handbook of Chemistry and Physics; Lide, D. R.; Ed.; CRC Press: Boca Raton, 1997-1998.

(65) Langmuir, I. The Constitution and Fundamental Properties of Solids and Liquids. Part I: Solids. J. Am. Chem. Soc. 1916, 38, 2221-2295.

(66) Shaw, D. J. Introduction to Colloid and Surface Chemistry, Butterworths: London, 1980.

(67) Jedlovszky, P.; Vincze, Á.; Horvai, G. New Insight into the Orientational Order of Water Molecules at the Water/1,2-Dichloroethane Interface: A Monte Carlo Simulation Study. J. Chem. Phys. 2002, 117, 2271-2280.

(68) Jedlovszky, P.; Vincze, Á.; Horvai, G. Full Description of the Orientational Statistics of Molecules Near to Interfaces. Water at the Interface with $\mathrm{CCl}_{4}$. Phys. Chem. Chem. Phys. 2004, 6, 1874-1879. 


\section{Tables}

Table 1. Data of the Adsorption Isotherm of Methylene Fluoride on Ice, As Obtained from the Simulations

\begin{tabular}{|c|c|c|c|}
\hline${ }^{\prime \mu} \mu / \mathrm{kJ} \mathrm{mol}^{-1}$ & $\langle\bar{l}\langle N\rangle$ & $\overline{p / p_{0}}$ & $\bar{l} \Gamma / \mu \mathrm{mol} \mathrm{m}{ }^{2}$ \\
\hline-45.13 & 0.037 & $3.92 \times 10^{-6}$ & $2.19 \times 10^{-3}$ \\
\hline-44.30 & 0.059 & $6.46 \times 10^{-6}$ & $3.51 \times 10^{-3}$ \\
\hline-43.47 & 0.11 & $1.06 \times 10^{-5}$ & $5.99 \times 10^{-3}$ \\
\hline-42.64 & 0.19 & $1.76 \times 10^{-5}$ & $1.01 \times 10^{-2}$ \\
\hline-41.81 & 0.28 & $2.89 \times 10^{-5}$ & $1.66 \times 10^{-2}$ \\
\hline-40.98 & 0.49 & $4.77 \times 10^{-5}$ & $2.90 \times 10^{-2}$ \\
\hline-40.14 & 0.76 & $7.87 \times 10^{-5}$ & $4.53 \times 10^{-2}$ \\
\hline-39.31 & 1.18 & $1.30 \times 10^{-4}$ & $7.03 \times 10^{-2}$ \\
\hline-38.48 & 1.73 & $2.14 \times 10^{-4}$ & 0.103 \\
\hline$-37.65^{a}$ & 2.76 & $3.53 \times 10^{-4}$ & 0.164 \\
\hline-36.82 & 4.26 & $5.81 \times 10^{-4}$ & 0.253 \\
\hline-35.99 & 7.13 & $9.59 \times 10^{-4}$ & 0.424 \\
\hline-35.16 & 10.34 & $1.58 \times 10^{-3}$ & 0.615 \\
\hline-34.32 & 15.81 & $2.61 \times 10^{-3}$ & 0.940 \\
\hline$-33.49^{b}$ & 22.91 & $4.30 \times 10^{-3}$ & 1.36 \\
\hline-32.66 & 31.11 & $7.08 \times 10^{-3}$ & 1.85 \\
\hline-31.83 & 43.72 & $1.17 \times 10^{-2}$ & 2.60 \\
\hline-31.00 & 58.92 & $1.93 \times 10^{-2}$ & 3.50 \\
\hline-30.17 & 77.92 & $3.18 \times 10^{-2}$ & 4.63 \\
\hline$-29.34^{c}$ & 99.58 & $5.23 \times 10^{-2}$ & 5.92 \\
\hline-28.50 & 123.1 & $8.63 \times 10^{-2}$ & 7.31 \\
\hline-27.67 & 157.8 & 0.142 & 9.38 \\
\hline-27.51 & 168.7 & 0.157 & 10.0 \\
\hline-27.34 & 185.7 & 0.174 & 11.0 \\
\hline-27.17 & 222.9 & 0.192 & 13.2 \\
\hline$-27.01^{\mathrm{d}}$ & 294.2 & 0.212 & 17.5 \\
\hline$-26.84^{\mathrm{e}}$ & 729.3 & 0.235 & 43.3 \\
\hline-26.01 & 745.9 & 0.387 & 44.3 \\
\hline-25.18 & 764.2 & 0.638 & 45.4 \\
\hline
\end{tabular}

${ }^{\mathrm{a}}$ system MeF 
Table 2. Data of the Adsorption Isotherm of Methylene Chloride on Ice. As Obtained from the Simulations

\begin{tabular}{|c|c|c|c|}
\hline$\mu / \mathrm{kJ} \mathrm{mol}^{-1}$ & $\langle\overline{|l| N\rangle}$ & $\bar{p} p / p_{0}$ & $\bar{l} \Gamma / \mu \mathrm{mol} \mathrm{m}{ }^{2}$ \\
\hline-46.36 & 0.0045 & $1.17 \times 10^{-3}$ & $2.67 \times 10^{-4}$ \\
\hline-45.53 & 0.0077 & $1.93 \times 10^{-3}$ & $4.58 \times 10^{-4}$ \\
\hline-44.70 & 0.012 & $3.18 \times 10^{-3}$ & $7.37 \times 10^{-4}$ \\
\hline-43.86 & 0.021 & $5.25 \times 10^{-3}$ & $1.23 \times 10^{-3}$ \\
\hline-43.03 & 0.034 & $8.65 \times 10^{-3}$ & $2.03 \times 10^{-3}$ \\
\hline-42.20 & 0.056 & $1.43 \times 10^{-2}$ & $3.35 \times 10^{-3}$ \\
\hline-41.37 & 0.088 & $2.35 \times 10^{-2}$ & $5.25 \times 10^{-3}$ \\
\hline-40.54 & 0.154 & $3.88 \times 10^{-2}$ & $9.14 \times 10^{-3}$ \\
\hline-39.71 & 0.256 & $6.39 \times 10^{-2}$ & $1.52 \times 10^{-2}$ \\
\hline-38.88 & 0.43 & 0.105 & $2.58 \times 10^{-2}$ \\
\hline-38.04 & 0.68 & 0.174 & $4.06 \times 10^{-2}$ \\
\hline-37.21 & 1.16 & 0.287 & $6.90 \times 10^{-2}$ \\
\hline$-36.38^{\mathrm{a}}$ & 2.15 & 0.473 & 0.128 \\
\hline-35.55 & 4.58 & 0.779 & 0.272 \\
\hline-35.38 & 5.13 & 0.861 & 0.305 \\
\hline$-35.21^{b}$ & 6.37 & 0.951 & 0.378 \\
\hline$-35.05^{\mathrm{c}}$ & 496.3 & & \\
\hline-34.88 & 502.3 & & \\
\hline-34.72 & 504.3 & & \\
\hline-33.89 & 506.7 & & \\
\hline-33.06 & 506.2 & & \\
\hline-32.22 & 503.6 & & \\
\hline-31.39 & 506.3 & & \\
\hline-30.56 & 509.9 & & \\
\hline
\end{tabular}


Table 3. Interaction Parameters of the Potential Models Used $(\sigma, \varepsilon$ and $q$ Being the Lennard-Jones Distance and Energy Parameters, and Fractional Charge, Respectively)

\begin{tabular}{ccccc}
\hline \hline molecule & atom & $\sigma / \AA$ & $\varepsilon / \mathrm{kJ} \mathrm{mol}^{1}$ & $q / \mathrm{e}$ \\
\hline \multirow{2}{*}{$\mathrm{CH}_{2} \mathrm{~F}_{2}$} & $\mathrm{C}$ & 3.150 & 0.4539 & 0.075 \\
& $\mathrm{H}$ & 2.170 & 0.0832 & 0.075 \\
& $\mathrm{~F}$ & 2.975 & 0.3356 & -0.225 \\
$\mathrm{H}$ & $\mathrm{O}$ & 3.120 & 0.6699 & 0.000 \\
& $\mathrm{H}$ & - & - & 0.241 \\
& $\mathrm{~L}^{\mathrm{a}}$ & - & - & -0.241 \\
$\mathrm{CH}_{2} \mathrm{Cl}_{2}$ & $\mathrm{C}$ & 3.200 & 0.4240 & 0.022 \\
& $\mathrm{H}$ & 2.750 & 1.1141 & 0.098 \\
& $\mathrm{Cl}$ & 3.350 & 1.4550 & -0.109 \\
\hline
\end{tabular}

\footnotetext{
${ }^{a}$ Non-atomic interaction site
} 
Table 4. Geometry Parameters of the Potential Models Used

\begin{tabular}{ccccc}
\hline \hline molecule & bond & bond length $(\AA)$ & angle & bond angle (deg) \\
\hline & $\mathrm{C}-\mathrm{H}$ & 1.0900 & & \\
$\mathrm{CH}_{2} \mathrm{~F}_{2}$ & $\mathrm{C}-\mathrm{F}$ & 1.3600 & $\mathrm{H}-\mathrm{C}-\mathrm{H}$ & 113.61 \\
& & $\mathrm{~F}-\mathrm{C}-\mathrm{F}$ & 108.63 \\
& $\mathrm{C}-\mathrm{H}$ & & & \\
& $\mathrm{C}-\mathrm{Cl}$ & 1.0850 & & 112.10 \\
$\mathrm{CH}_{2} \mathrm{Cl}_{2}$ & & & $\mathrm{H}-\mathrm{C}-\mathrm{H}$ & 112.20 \\
& & $\mathrm{Cl}-\mathrm{C}-\mathrm{Cl}$ & \\
& $\mathrm{O}-\mathrm{H}$ & & \\
$\mathrm{H}_{2} \mathrm{O}$ & 0.9572 & $\mathrm{H}-\mathrm{O}-\mathrm{H}$ & 104.50 \\
& & & $\mathrm{~L}-\mathrm{O}-\mathrm{L}$ & 110.70 \\
\hline \hline
\end{tabular}




\section{Figure Legend}

Figure 1. Adsorption isotherm of methylene fluoride (black) and methylene chloride (red) at the surface of $I_{h}$ ice, as obtained from our simulations. The lines connecting the points are just guides to the eye. The arrows show the systems that have been used for detailed analyses.

Figure 2. Instantaneous equilibrium snapshots of the adsorption layer of (a) methylene fluoride, and (b) methylene chloride at the ice surface, as obtained from the simulation of the systems MeF I (panel a, top row), MeF II (panel a, second row), MeF III (panel a, third row), MeF IV (panel a, fourth row), MeF V (panel a, bottom row), $\mathrm{MeCl}$ I (panel b, top row), $\mathrm{MeCl}$ II (panel b, middle row), and $\mathrm{MeCl}$ III (panel b, bottom row) in side view (first columns) and top view (second columns). $\mathrm{H}, \mathrm{O}, \mathrm{C}$ and $\mathrm{F} / \mathrm{Cl}$ atoms are shown by light grey, red, grey and yellow colors, respectively.

Figure 3. The adsorption isotherm calculated for methylene fluoride, shown in the conventional surface density vs. relative pressure form (black circles). The dashed red curve shows the Langmuir isotherm fitted to the calculated data points up to the $p / p_{0}$ value of 0.0523 , whereas the dash-dotted blue curve corresponds to the BET isotherm fitted to the calculated date points up to the $p / p_{0}$ value of 0.15 . The inset shows the same isotherm for methylene chloride. The black solid lines connecting the symbols are just guides to the eye. 
Figure 4. Number density profile of the methylene fluoride (top panel) and methylene chloride (bottom panel) molecules along the surface normal axis $X$, for $\mathrm{CH}_{2} \mathrm{~F}_{2}$ at the chemical potential values of $-37.65 \mathrm{~kJ} / \mathrm{mol}$ (system MeF I, red dash-dot-dotted line), $-33.49 \mathrm{~kJ} / \mathrm{mol}$ (system MeF II, green dash-dotted line), -29.34 kJ/mol (system MeF III, orange dashed line), -27.01 kJ/mol (system MeF IV, magenta short dashed line), and $-26.84 \mathrm{~kJ} / \mathrm{mol}$ (system MeF V, blue open circles), and for $\mathrm{CH}_{2} \mathrm{Cl}_{2}$ at the chemical potential values of $-36.38 \mathrm{~kJ} / \mathrm{mol}$ (system $\mathrm{MeCl} \mathrm{I}$, red dash-dot-dotted line), $-35.21 \mathrm{~kJ} / \mathrm{mol}$ (system $\mathrm{MeCl} \mathrm{II}$, green dash-dotted line), and $-35.05 \mathrm{~kJ} / \mathrm{mol}$ (system $\mathrm{MeCl}$ III, blue open circles). Part of the number density of the water molecules is also shown (black solid lines). The dotted vertical lines mark the boundary of the first molecular layer. The inset shows the water number density profile in the entire ice phase of system MeF I. All profiles shown are symmetrized over the two ice surfaces present in the basic simulation box.

Figure 5. Definition of the local Cartesian frame fixed to the individual $\mathrm{CH}_{2} \mathrm{~F}_{2}$ and $\mathrm{CH}_{2} \mathrm{Cl}_{2}$ molecules ( $\mathrm{R}$ stands for $\mathrm{F}$ or $\mathrm{Cl}$ ), and of the polar angles $\vartheta$ and $\phi$ of the surface normal axis, $\underline{X}$, pointing, by our convention, from the ice to the vapor phase, in this frame. Color coding of the atoms is the same as in Fig. 2.

Figure 6. Orientational maps of the methylene fluoride (top row) and methylene chloride (bottom row) molecules, located in the first molecular layer at the ice surface, as obtained at various chemical potential values. Lighter shades of grey correspond to higher probabilities. The preferred orientations of the adsorbed molecules are also illustrated at the bottom of the Figure. Color coding of the atoms is the same as in Fig. 2.

Figure 7. Illustration of the possible relative arrangements of a first layer adsorbed methylene fluoride or methylene chloride and a surface water molecule, in which both molecules are in one of their preferred alignments and they can form a hydrogen bond with each other. The hydrogen bond between the two molecules is marked by a dashed line. Color coding of the atoms is the same as in Fig. 2. 
Figure 8. Distribution of the total binding energy (i.e., interaction energy with the rest of the system, bottom panels) of an adsorbed molecule belonging to the first molecular layer at the ice surface, and of its contributions coming from the interaction with the other adsorbed molecules (middle panels) and with the ice phase (top panels), as obtained for the adsorption of (a) methylene fluoride, and (b) methylene chloride at various chemical potential values. 
Figure 1

Sumi et al.

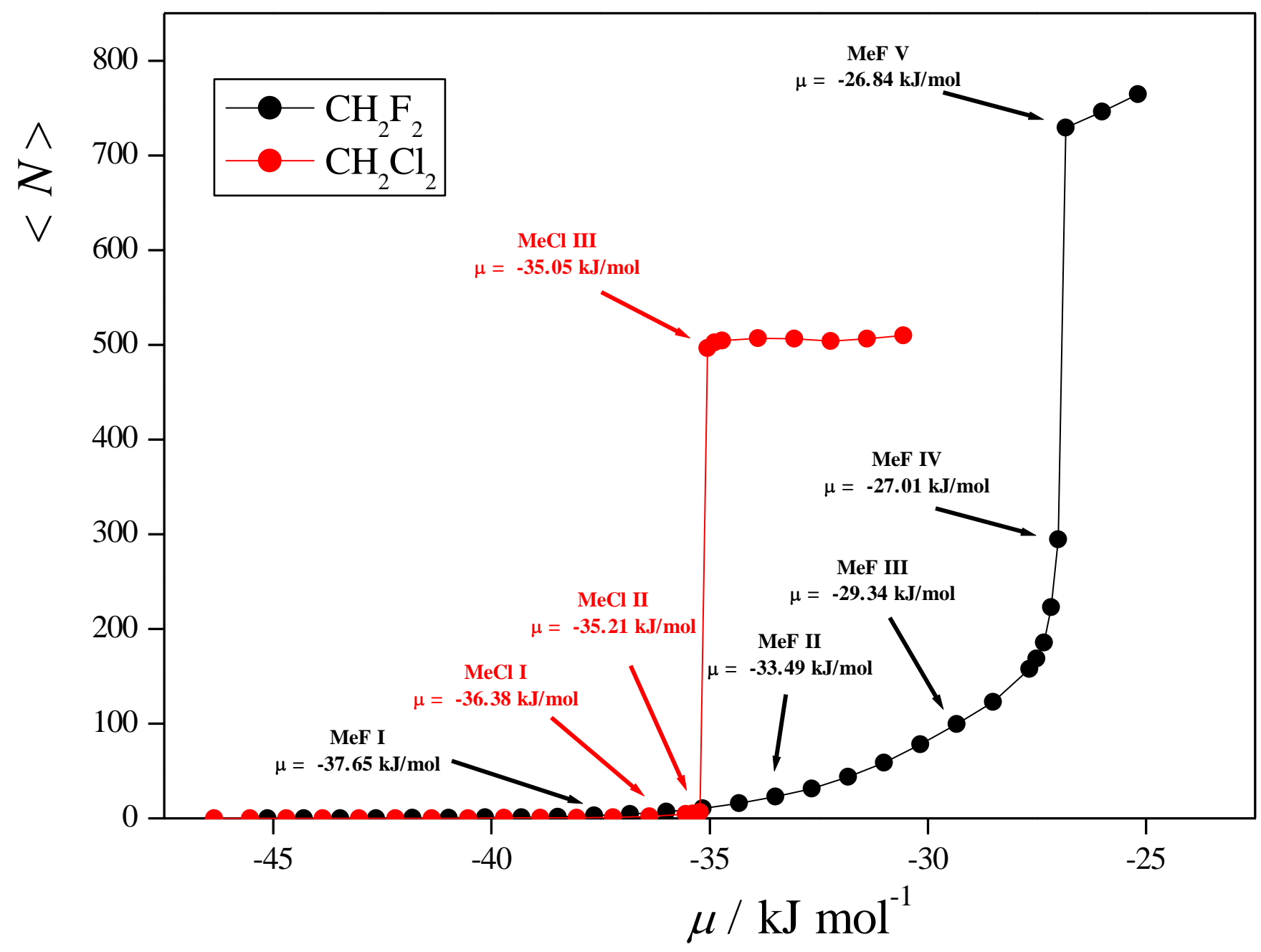


Figure 2.a

Sumi et al.

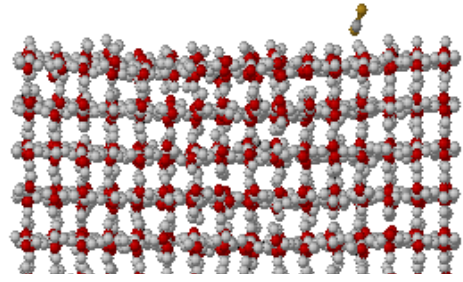

$$
\begin{gathered}
\text { MeF I } \\
\mu=-37.65 \mathrm{~kJ} / \mathrm{mol}
\end{gathered}
$$

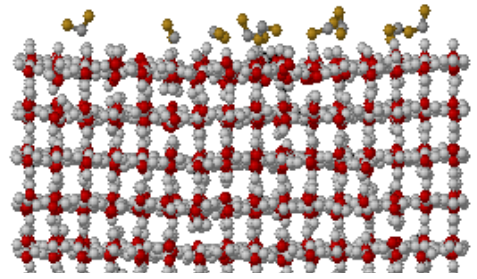

$$
\begin{gathered}
\text { MeF II } \\
\mu=-33.49 \mathrm{~kJ} / \mathrm{mol}
\end{gathered}
$$

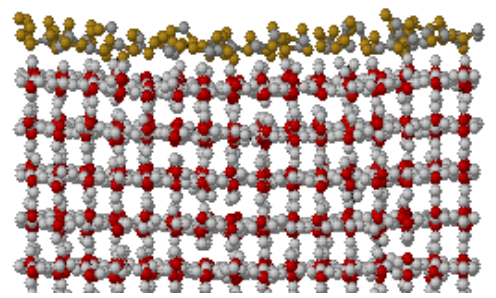

$$
\begin{gathered}
\text { MeF III } \\
\mu=\mathbf{- 2 9 . 3 4} \mathrm{kJ} / \mathrm{mol}
\end{gathered}
$$

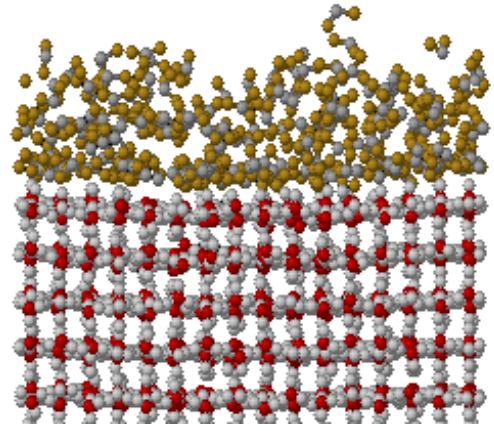

$$
\begin{gathered}
\text { MeF IV } \\
\mu=-\mathbf{2 7 . 1 0} \mathrm{kJ} / \mathrm{mol}
\end{gathered}
$$

MeF V

$\mu=-26.84 \mathrm{~kJ} / \mathrm{mol}$
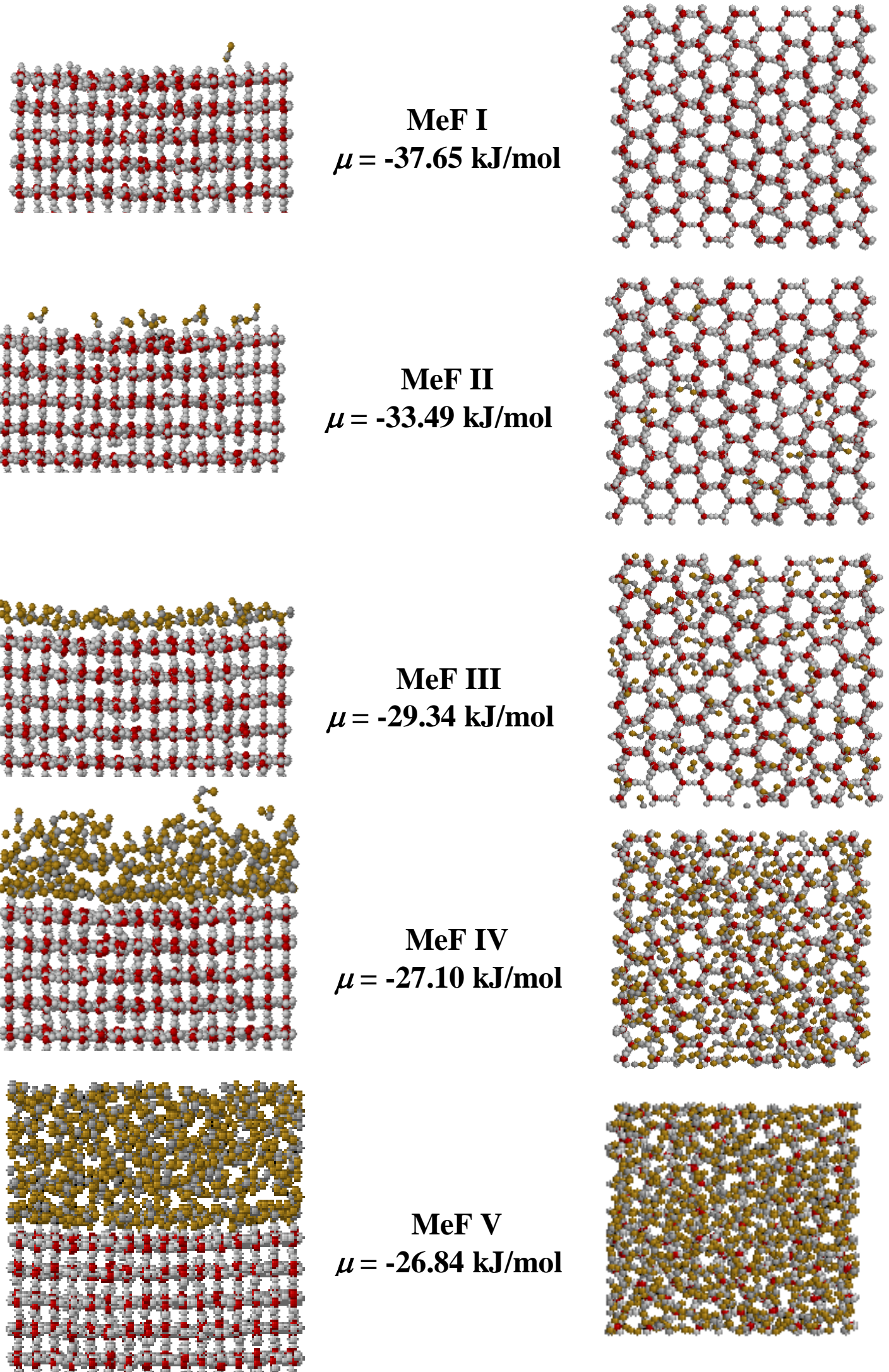
Figure 2.b

Sumi et al.

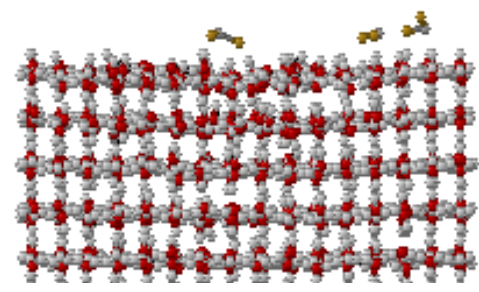

$$
\begin{gathered}
\text { MeCl I } \\
\mu=-36.38 \mathrm{~kJ} / \mathrm{mol}
\end{gathered}
$$
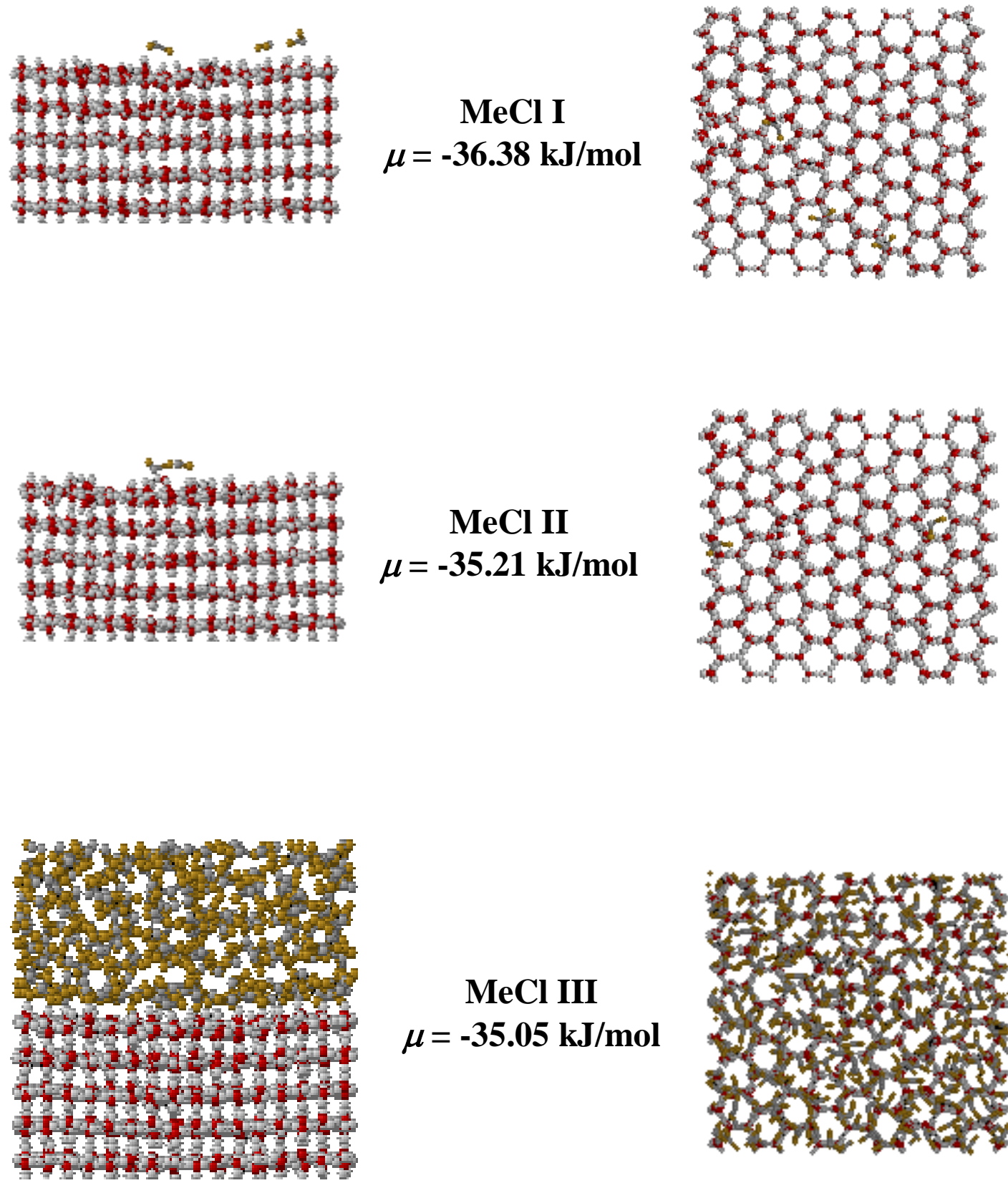

\section{MeCl III

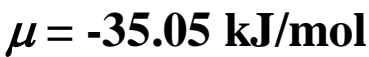

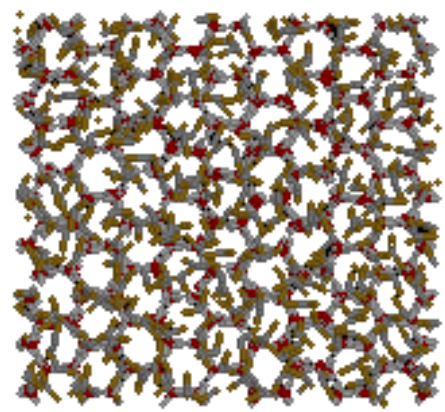


Figure 3

Sumi et al.

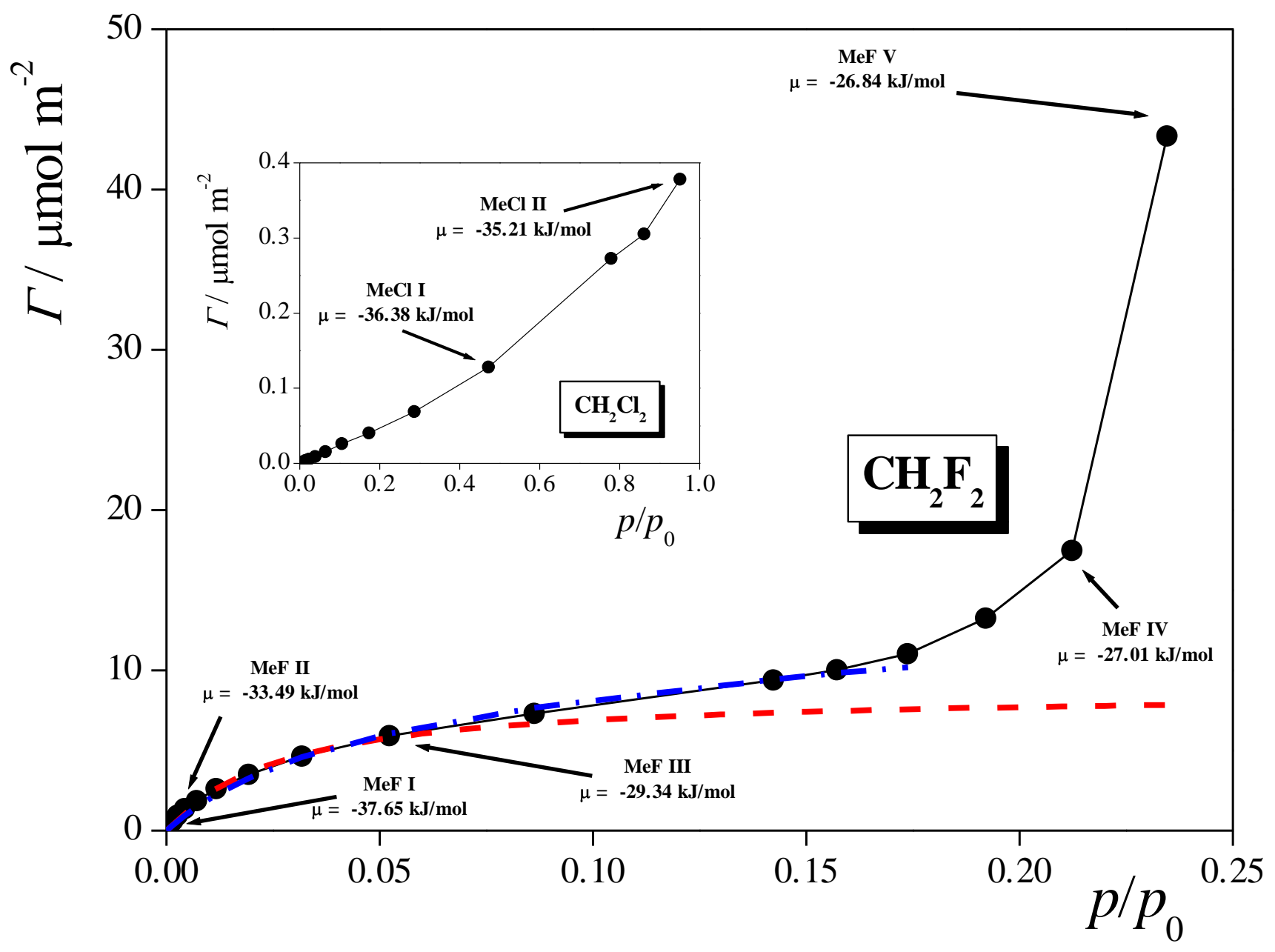


Figure 4

Sumi et al.

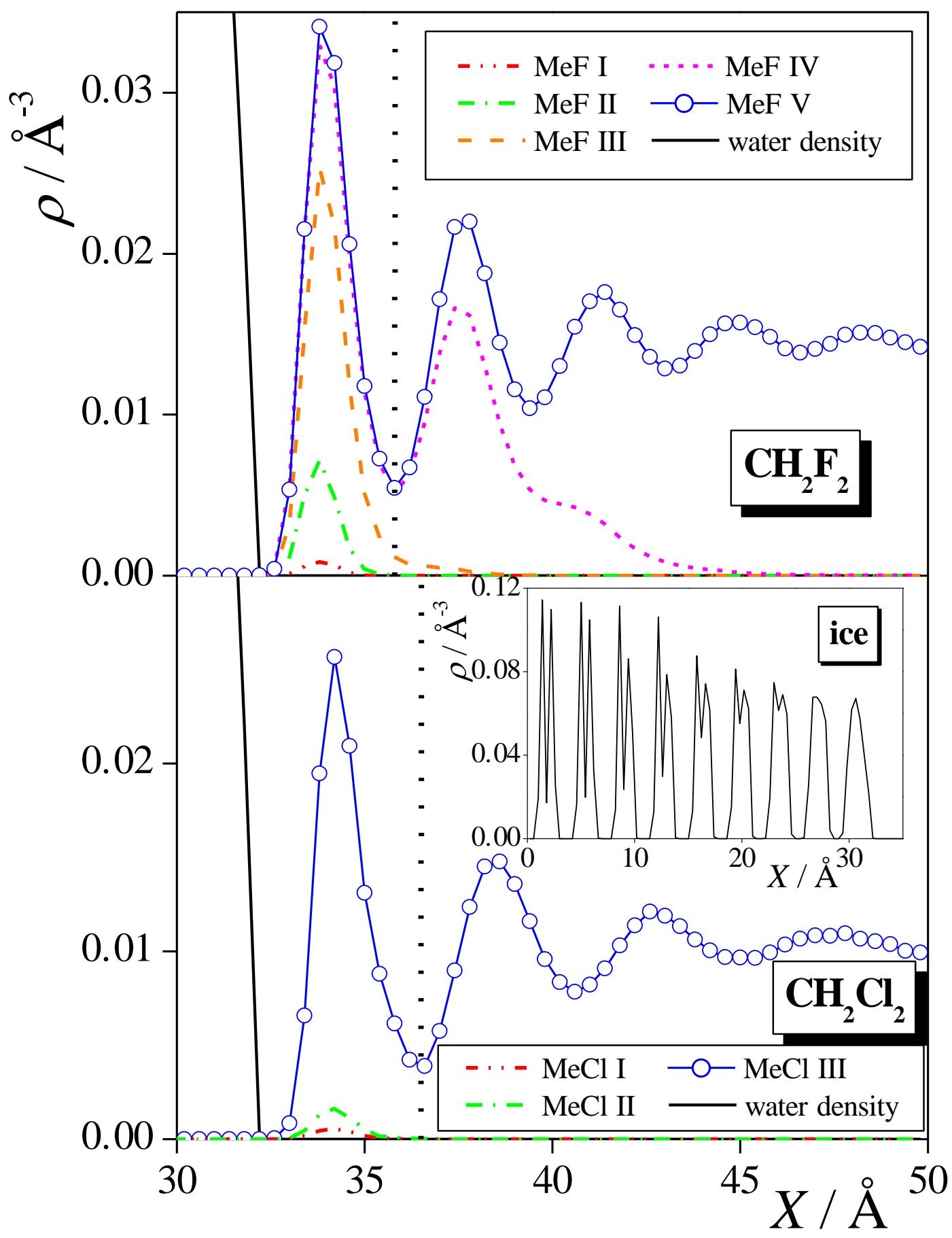


Figure 5

Sumi et al.

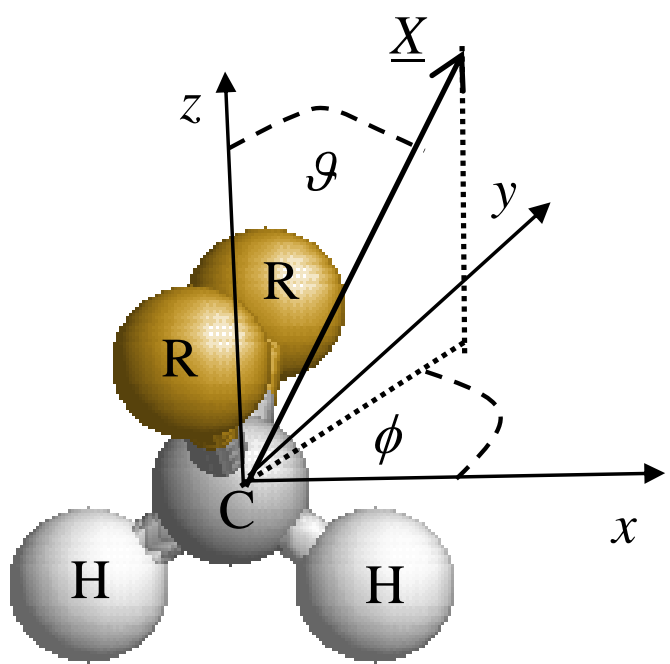


Figure 6

Sumi et al.
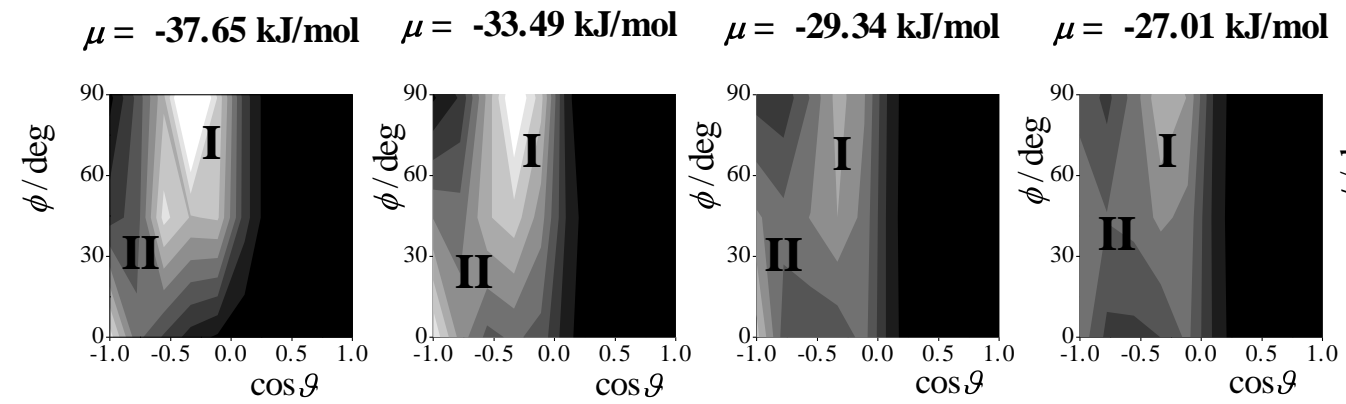

$\mu=-26.84 \mathrm{~kJ} / \mathrm{mol}$

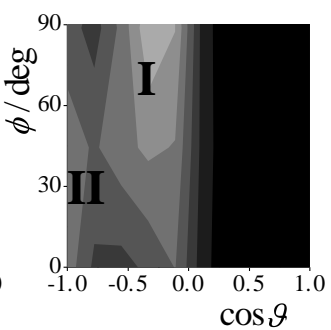

$\mathrm{CH}_{2} \mathrm{~F}_{2}$
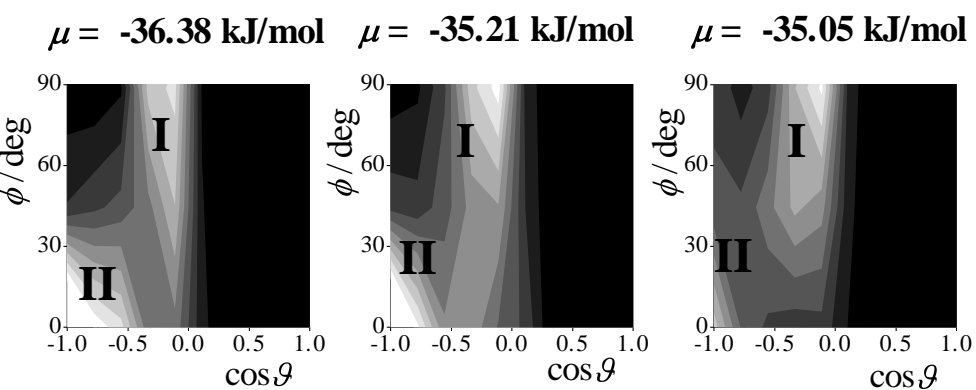

$\mathrm{CH}_{2} \mathrm{Cl}_{2}$
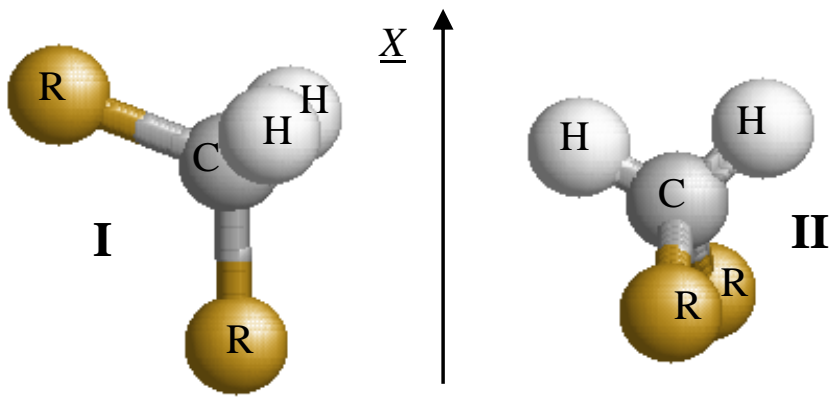
Figure 7

Sumi et al.
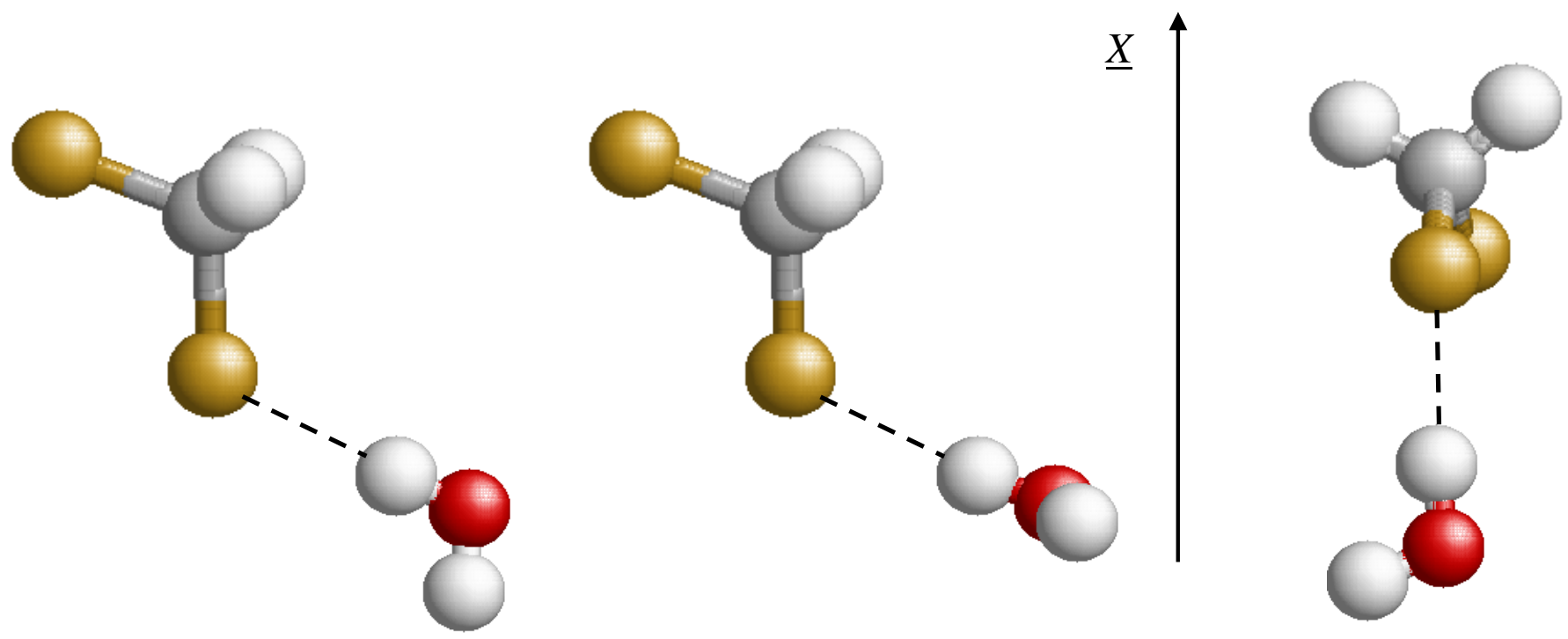
Figure 8

Sumi et al.

(a)
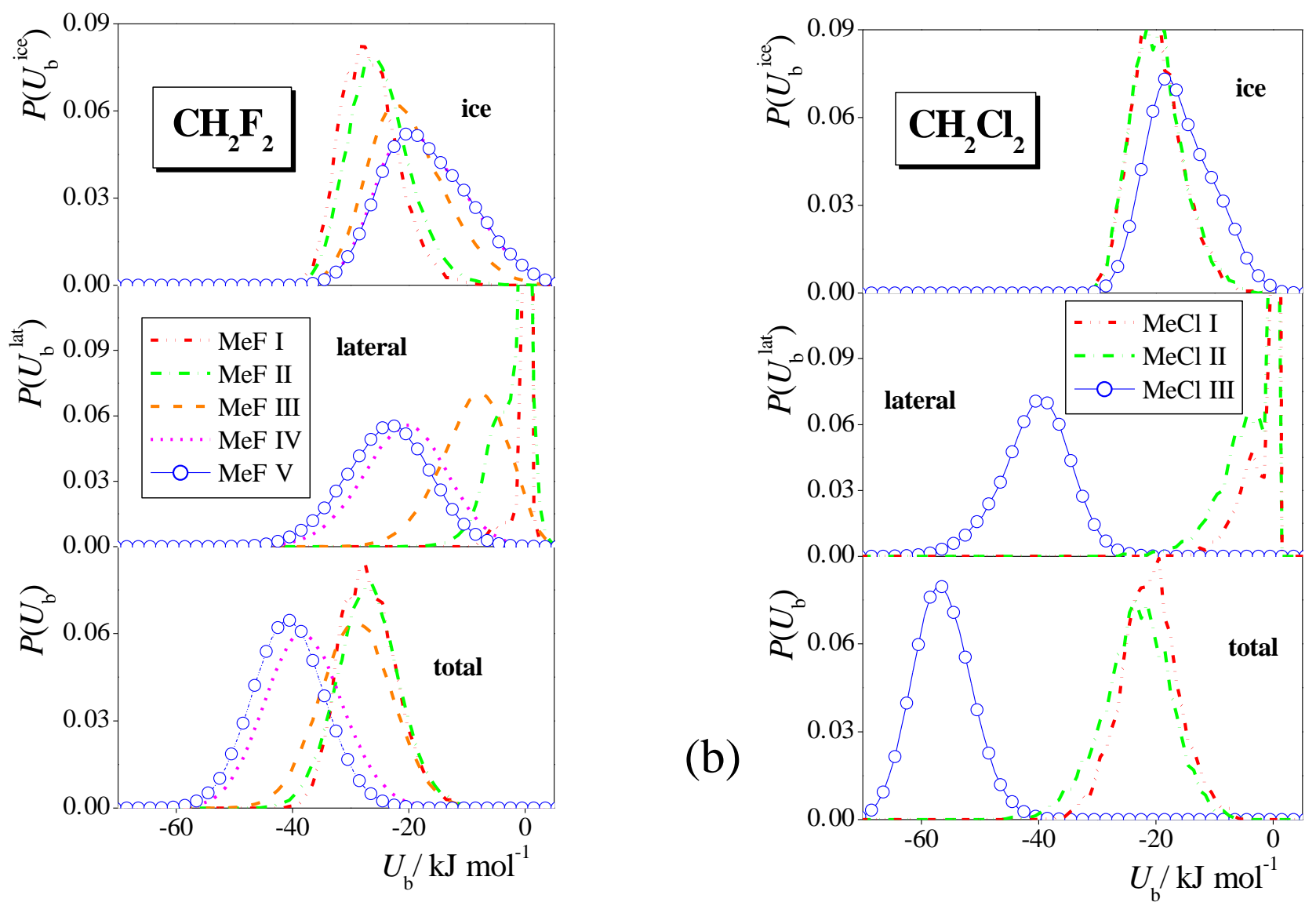
Table of Contents Graphics:

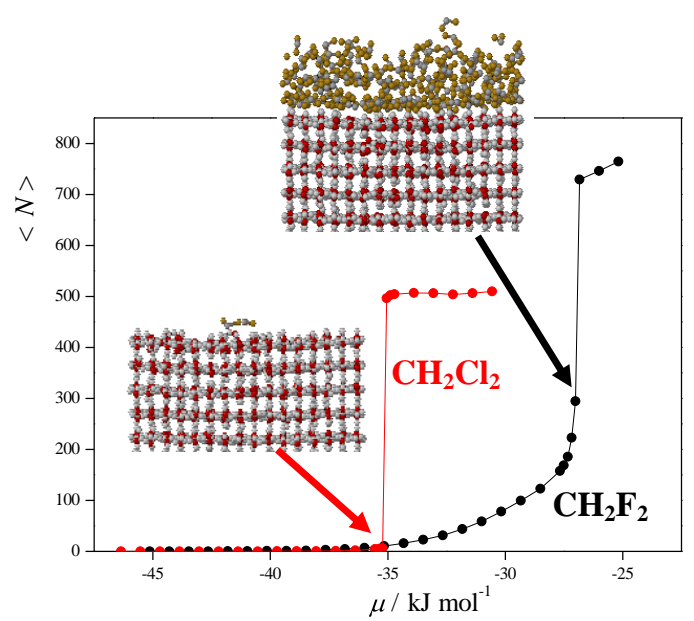

